\title{
Sphaerospora elwhaiensis sp.n. (Myxosporea: Sphaerosporidae) from landlocked sockeye salmon Oncorhynchus nerka (Salmoniformes: Salmonidae) in Washington State, USA
}

\author{
Simon Jones ${ }^{1}$, Ivan Fiala ${ }^{2}$, Gina Prosperi-Porta ${ }^{1}$, Marcia House $^{3}$ and Sonia Mumford ${ }^{4}$ \\ ${ }^{1}$ Pacific Biological Station, Fisheries and Oceans Canada, 3190 Hammond Bay Road, Nanaimo, British Columbia V9T 6N7, \\ Canada; \\ ${ }^{2}$ Institute of Parasitology, Biology Centre of the Academy of Sciences of the Czech Republic, Branišovská 31, 37005 České \\ Budějovice, Czech Republic; \\ ${ }^{3}$ Northwest Indian Fisheries Commission, 6730 Martin Way East, Olympia, Washington 98516, USA; \\ ${ }^{4}$ U.S. Fish and Wildlife Service, Olympia Fish Health Center, 3859 Martin Way East Suite 101, Olympia, Washington 98506, USA
}

\begin{abstract}
A new species of sphaerosporid myxosporean, Sphaerospora elwhaiensis sp. n., is described from kidney of non-anadromous sockeye salmon (kokanee) Oncorhynchus nerka (Walbaum) from Lake Sutherland in the northern Olympic Peninsula, Washington, USA. Infection with the parasite was detected in $45 \%$ of 177 kokanee examined over 5 years. While conforming to the morphological criteria by which members of the genus are defined, the parasite is distinguished from congeners in salmonids of western North America by a unique combination of valvular sculpting of the myxospore, the relatively large size of the myxospore and monosporous development within the pseudoplasmodium. In addition, nucleotide sequences of the parasite's small and large subunit ribosomal RNA gene are unique. Phylogenetic analyses of these sequences suggested that the parasite is most closely related to freshwater Myxidium spp. and Zschokkella spp. The molecular data have provided further evidence for a polyphyletic association previously recognized among members of the genus and emphasize the need for a taxonomic revision of Sphaerospora Thélohan, 1892 and related genera.
\end{abstract}

Keywords: Sphaerospora elwhaiensis, Myxozoa, Myxosporea, kokanee, Oncorhynchus nerka

Myxosporeans belonging to the genus Sphaerospora Thélohan, 1892 (Variisporina, Sphaerosporidae) are coelozoic parasites in the urinary system of freshwater and marine fish and occasionally, amphibians (Lom and Dyková 2006). Approximately 78 species have been described according to the size and morphology of the myxospore that is typically spherical to sub-spherical with a prominent sutural ridge and polar capsules that are spherical to subspherical (Lom and Dyková 2006, Jirků et al. 2007). Three species of Sphaerospora have been reported from salmoniform fishes: S. truttae Fischer-Scherl, El-Matbouli et Hoffmann, 1986 from brown trout Salmo trutta L., grayling Thymallus thymallus (L.) and Atlantic salmon Salmo salar L. in Germany and the United Kingdom, S. coregoni El-Matbouli, Hoffmann et Kern, 1995 from whitefish Coregonus lavaretus (L.) in Germany and Switzerland and S. oncorhynchi Kent, Whitaker et Margolis, 1993 from anadromous sockeye salmon Oncorhynchus nerka (Walbaum) in British Columbia, Canada (FischerScherl et al. 1986, Walter et al. 1991, Kent et al. 1993,
El-Matbouli et al. 1995, McGeorge et al. 1997, Holzer et al. 2004). Unidentified sphaerosporids have also been reported from Atlantic salmon in eastern North America (Bennett and Wolke 1986) and from rainbow trout Oncorhynchus mykiss (Walbaum) in California and Washington State, USA (Hedrick et al. 1988).

The Elwha River drains a watershed of approximately 700 square kilometres centrally along the north shore of the Olympic Peninsula in Washington State, USA. Almost 100 years ago the construction of dams approximately $6.5 \mathrm{~km}$ upstream from the mouth of the Elwha River effectively blocked the movement of anadromous fish. The scheduling of these dams for removal has provided an opportunity to understand the health implications to resident salmonids caused by the reintroduction of anadromous fish to the watershed (Brenkman et al. 2008). The present study describes a morphologically and genetically distinct sphaerosporid parasite from the renal tubules of landlocked sockeye salmon (kokanee) from Lake Sutherland located in the northwest quadrant of the Elwha 
River watershed. The relatedness of the new species to its congeners and the apparent phylogenetic affinities of Sphaerospora, as inferred from large and small subunit ribosomal DNA sequence data, are discussed.

\section{MATERIALS AND METHODS}

Fish. Specimens were collected from the kokanee population in Lake Sutherland every October from 2005 to 2009, by setting a series of gill nets for 1-2 hr. The fish were immediately put on ice and fork length and weight data and tissue samples were obtained 3-4 hr after capture. Portions of mid-trunk kidney were placed into $10 \%$ neutral buffered formalin, $95 \%$ ethanol or $4 \%$ glutaraldehyde. In 2007 , an additional portion of kidney from each fish was placed into a separate tube containing Hanks' balanced salt solution (HBSS) supplemented with penicillin and streptomycin.

Spore suspensions. Kidney homogenates in HBSS were prepared as described earlier (Jones et al. 2006) and the presence of sphaerospores confirmed microscopically. A small volume of the spore suspension was placed onto a thin layer of agar on a glass slide as described by Lom (1969) and examined by phase contrast microscopy. Drawings of spores were prepared with the aid of a microscope drawing tube calibrated using a stage micrometer and spore dimensions were obtained directly from the drawings.

Histology. Formalin-preserved kidney samples were dehydrated through an isopropanol gradient, cleared in xylene and embedded in paraffin wax. Histological sections ( 3 or $5 \mu \mathrm{m})$ were mounted on glass slides, stained with haematoxylin and eosin, Giemsa, Gram, periodic acid-Schiff or Sudan black stains, coverslipped and examined using a compound microscope. Digital photomicrographs of histological sections and suspended intact spores were taken using a Zeiss Axio Imager compound microscope equipped with an Axiocam MRc5.

Transmission electron microscopy. Kidney samples preserved in glutaraldehyde were washed with $0.1 \mathrm{M}$ Sorenson's buffer, post-fixed $1 \mathrm{hr}$ with $1 \% \mathrm{OsO}_{4}$, washed with $50 \%$ ethanol and stained for $1 \mathrm{hr}$ with $5 \%$ uranyl acetate. Tissues were dehydrated through an alcohol gradient, two changes of absolute alcohol and two of acetone. Tissues were incubated overnight in a 50:50 mixture of acetone and epoxy resin (Jembed 812, Canemco Inc.) followed by a 6-7 hour incubation in $100 \%$ resin at $60^{\circ} \mathrm{C}$. Tissue blocks were trimmed and cut on a Reichert-Jung Ultracut E ultramicrotome (Leica Microsystems). Semithin sections of $0.5 \mu \mathrm{m}$ were mounted on glass slides and stained with $1 \%$ toluidine blue for light microscopy. Ultrathin sections of less than $100 \mathrm{~nm}$ were stained with 5\% uranyl acetate and lead Sato stain (a mixture of lead acetate, lead nitrate and lead citrate), mounted onto 200 mesh copper super grids and viewed at $80 \mathrm{kV}$ with a Hitachi TEM 7500 (Nissei-Sangyo). Digital images were captured with an AMT HR40 camera (Advanced Microscopy Techniques).

DNA extraction and polymerase chain reactions (PCR). DNA was extracted using the animal tissue protocol (DNeasy Blood and Tissue kits, Qiagen Inc.) from approximately $35 \mathrm{mg}$ of ethanol-fixed kidney into $\mathrm{AE}$ buffer and quantified using a Nanodrop-1000 spectrophotometer (v. 3.2.1). Small subunit ribosomal DNA (SSU rDNA) was initially amplified using primers $18 \mathrm{E}$ and $18 \mathrm{G}$ (Table 1 ) in a mixture containing $2.5 \mu \mathrm{l}$
Table 1. Oligonucleotide primers used to amplify portions of the small and large subunit ribosomal RNA genes from Sphaerospora elwhaiensis sp. n.

\begin{tabular}{|c|c|c|}
\hline Primer name & Primer sequence $\left(5^{\prime}-3^{\prime}\right)$ & Reference \\
\hline $18 \mathrm{E}$ & TGGTTGATCCTGCCAGT & $\begin{array}{l}\text { Hillis and } \\
\text { Dixon } 1991\end{array}$ \\
\hline Myx1F & GTGAGACTGCGGACGGCTCAG & $\begin{array}{l}\text { Hallett and } \\
\text { Diamant } 2001\end{array}$ \\
\hline Myxgp2F & WTGGATAACCGTGGGAAA & $\begin{array}{l}\text { Kent et } \\
\text { al. } 1998\end{array}$ \\
\hline SK3F & CAATCCAGACACTGGGAGGT & Present study \\
\hline SK1F & TGTTGAATTGGGCTGTGGTA & Present study \\
\hline SK3R & TGTACCACAGCCCAATTCAA & Present study \\
\hline Act1R & AATTTCACCTCTCGCTGCCA & $\begin{array}{l}\text { Hallett and } \\
\text { Diamant } 2001\end{array}$ \\
\hline SK6R & CAGGTGAGTTTTCCCGTGTT & Present study \\
\hline MX3R & CCAGGACATCTTAGGGCATCACAGA & $\begin{array}{l}\text { Andree et } \\
\text { al. } 1998\end{array}$ \\
\hline $18 \mathrm{G}$ & GGTAGTAGCGACGGGCGGTGTG & $\begin{array}{l}\text { Hillis and } \\
\text { Dixon } 1991\end{array}$ \\
\hline NLFfMyxid & AATGCTAGGGTTCCRAGTGG & $\begin{array}{l}\text { Bartošová } \\
\text { et al. } 2009\end{array}$ \\
\hline NLR3113 & GTCTAAACCCAGCTCACGTTCCCT & $\begin{array}{l}\text { Bartošová } \\
\text { et al. } 2009\end{array}$ \\
\hline
\end{tabular}

$10 \times$ PCR buffer; $2.5 \mu 12 \mathrm{mM}$ dNTPs; $0.75 \mu 150 \mathrm{mM} \mathrm{MgCl}_{2}$; $0.5 \mu$ each $10 \mu \mathrm{M}$ primer; $0.125 \mu \mathrm{l}$ Platinum taq DNA polymerase; $1-2 \mu$ DNA template, and DNAse- and RNAse-free water to a final volume of $25 \mu \mathrm{l}$ (all reagents Invitrogen). Subsequent PCR amplifications and sequencing of SSU rDNA used the initial PCR product as template DNA and the myxozoan-specific primers listed in Table 1. PCR amplification consisted of $95^{\circ} \mathrm{C}$ for $3 \mathrm{~min}$, and 35 cycles of $94^{\circ} \mathrm{C}$ for $45 \mathrm{sec}, 52^{\circ} \mathrm{C}$ to $66.5^{\circ} \mathrm{C}$ (primer dependent) for $45 \mathrm{sec}, 72^{\circ} \mathrm{C}$ for $90 \mathrm{sec}$ followed by $72^{\circ} \mathrm{C}$ for $10 \mathrm{~min}$. Purified (ExoSap-it, GE Healthcare) products from the PCR amplification of SSU rDNA from 3 infected kokanee tissue collected in 2006 were directly sequenced using BigDye Terminator V 3.1 (Applied Biosystems). Each $10 \mu 1$ sequencing reaction contained $1-3 \mu 1$ of PCR product, $0.5 \mu 1$ of 3.2 pmols of each primer, $1 \mu \mathrm{l}$ BigDye Terminator V3.1, and $2 \mu \mathrm{l} 5 \times$ BDT buffer $\left(200 \mathrm{mM}\right.$ Tris pH 8.6, $\left.5 \mathrm{mM} \mathrm{MgCl}_{2}\right)$ in $\mathrm{ddH}_{2} \mathrm{O}$. Reactions consisted of an initial denaturation at $96^{\circ} \mathrm{C}$ for $1 \mathrm{~min}$ and $25 \mathrm{cycles}$ of $96^{\circ} \mathrm{C}$ for $10 \mathrm{sec}, 50^{\circ} \mathrm{C}$ for $5 \mathrm{sec}$ and $60^{\circ} \mathrm{C}$ for $4 \mathrm{~min}$. Reaction products were purified (DyeEx 2.0, Qiagen Inc.), rehydrated with $10 \mu 1$ formamide and sequenced using a 48-capillary DNA analyzer (Applied Biosystems). The sequences were edited and assembled into a consensus sequence by using Sequencher 4.9 (Gene Codes Corporation, Ann Arbor, MI).

Similarly, partial large subunit (LSU) rDNA was amplified by NLFfMyxid and NLR3113 primers (Table 1). The PCR was performed in a $25 \mu \mathrm{l}$ reaction volume using $10 \mathrm{pmol}$ of each primer, $250 \mu \mathrm{m}$ of each $\mathrm{dNTP}$, and $2.5 \mu 110 \times$ PCR buffer and 1 unit of Taq-Purple polymerase (Top-Bio). Amplification consisted of 30 cycles of $95^{\circ} \mathrm{C}$ for $1 \mathrm{~min}, 48^{\circ} \mathrm{C}$ for $1 \mathrm{~min}$ and $72^{\circ} \mathrm{C}$ for $2 \mathrm{~min}$, followed by $10 \mathrm{~min}$ incubation at $72^{\circ} \mathrm{C}$. The PCR products were isolated from the gel and cloned into pDrive Cloning Vector using Qiagen PCR Cloning Kit (Qiagen). Both DNA strands from a single clone of the PCR product were sequenced on an ABI PRISM 3130xl automatic sequencer (Applied Biosystems). 
The top 6 homologous sequences obtained by BLASTn analysis (http://blast.ncbi.nlm.nih.gov/Blast.cgi) of the SSU rDNA sequence (Chloromyxum trijugum AY954689, Zschokkella icterica DQ333434, Myxidium scripta DQ851568, M. truttae AF201374, Z. nova DQ377688, Zschokkella sp. FJ361238) and those from 7 other Sphaerospora spp. (S. testicularis HM230825, S. dicentrarchi FJ417074, S. renicola AY735410, S. elegans AJ609590, S. oncorhynchi AF201373, S. molnari AF378345, S. truttae AJ581915) obtained from GenBank were subjected to multiple alignments using ClustalW in MEGA 4.1(Tamura et al. 2007). Pairwise genetic distances, based on 843 nucleotide positions, were calculated using the Kimura 2-parameter method, with complete gaps deletion. The standard error associated with each distance was estimated by a 1000 -fold bootstrapping procedure.

Phylogenetic analysis. The phylogenetic position of the parasite was inferred from combined SSU and LSU rDNA data. The alignment consisted of $26 \mathrm{SSU}$ and $15 \mathrm{LSU}$ concatenated rDNA sequences (GenBank accession numbers are in Fig. 4). A multiple alignment was performed using MAFFT v6.626b (Katoh et al. 2002) with default parameters. Ambiguous characters were removed by GBlocks $0.91 \mathrm{~b}$ (Castresana 2000) with the parameters $14,18,8,8$ for the SSU rDNA alignment and $8,9,8,8$ for the LSU rDNA alignment.

Additional alignments were constructed from ten closely related species that have both SSU and LSU rDNA sequences available. The alignments were adjusted using GBlocks with default parameters for both single rDNA analyses. Concatenated rDNA alignment was adjusted by five different sets of GBlocks parameters resulting into five alignments with different lengths. Analyses of individual SSU and LSU rDNA sequences were performed as well as analyses of combined SSU+LSU rDNA sequences, with different GBlocks settings.

The phylogenetic trees were constructed by maximum likelihood (ML), maximum parsimony (MP) and Bayesian inference (BI). ML and MP analyses were carried out with the program package PAUP*, Version 4.0b10 (Swofford 2001). To obtain the best tree using ML analysis the likelihood ratio test (LRT) implemented in the Modeltest 3.7 (Posada and Crandall 1998) was used, in which the GTR $+\mathrm{I}+\Gamma$ model of evolution was found to fit the data best. The MP analysis was done using heuristic search with random addition of taxa (10 replications) and the ACCTRAN-option. Gaps were treated as missing data and transition/transversion ratio was set to $1: 2$. Clade support was assessed with bootstrapping (500 replicates). BI analysis was inferred using MrBayes v. 3.1.2 (Ronquist and Huelsenbeck 2003). The most parameter rich model (GTR with estimates of invariant sites and gamma distributed among site rate variation) was found by MrModeltest2 (Nylander 2004) to fit the data best. The MCMC processes were set so that four chains were run simultaneously for 1,000,000 generations. Burn-in was determined to 100,000 generations.

Statistical analysis. The statistical significance of the difference in mean fork length for each 2 year comparison was estimated by using a two-sample $t$-test. For histological and PCR determinations of prevalence, each estimate of the statistical significance of the difference between 2 years was determined by using a Chi-square test. Within a year, a Chi-square test was used to compare the prevalence obtained by histology and PCR. For all tests, the differences were considered statistically significant when $\mathrm{p}<0.05$.

\section{RESULTS}

The definition of the genus Sphaerospora Thélohan, 1892 (sensu lato) is reported in Lom and Dyková (2006). A new species of myxozoan parasite bearing morphological characters of the genus (Fig. 1) is described from the kidney of Oncorhynchus nerka in the northwest USA.

\section{Sphaerospora elwhaiensis sp. n.}

Figs. 1-3

Description. Spores subspherical with prominent sutural ridge, two symmetrical and sculpted valves, each with thickened anterior extremity. Mean length ( \pm 1 S.D.) of fresh spores $10.3 \pm 0.6 \mu \mathrm{m}$ (range 9.3-12.0 $\mu \mathrm{m}$ ) and width $11.2 \pm 0.9 \mu \mathrm{m}$ (range 9.9-14.3 $\mu \mathrm{m}$ ); two spherical polar capsules, equal in size with mean diameter $3.3 \pm 0.5 \mu \mathrm{m}$ (range $2.4-4.5 \mu \mathrm{m})(\mathrm{n}=34)$. Polar filament flattened in profile, coiling six times within polar capsule. Two uninucleate sporoplasms. Early trophozoite mononucleate to multinucleate. Pseudoplasmodium monosporous with single nucleus.

Type host: Oncorhynchus nerka (Walbaum, 1792) (Salmoniformes, Salmonidae).

Type locality: Lake Sutherland, Clallam County, Washington, USA $\left(48^{\circ} 05^{\prime} \mathrm{N} ; 123^{\circ} 43^{\prime} \mathrm{W}\right)$.

Site of infection: Renal tubules.
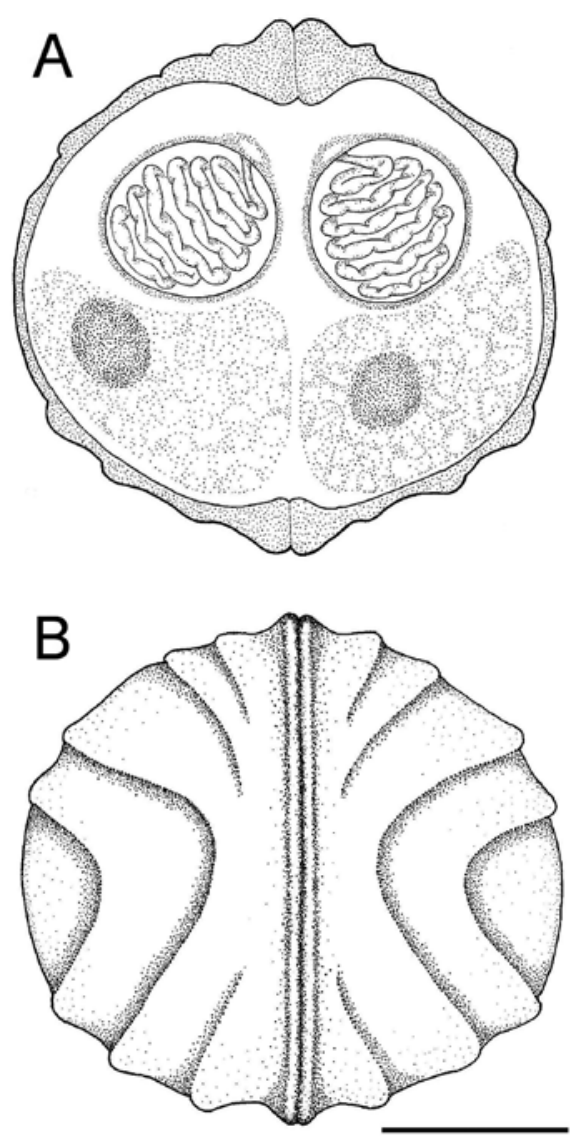

Fig. 1. Line drawing of Sphaerospora elwhaiensis sp. n. based on fresh material; lateral views of myxospore. A - internal anatomy; B - valvular sculpting. Scale bar $=4 \mu \mathrm{m}$. 


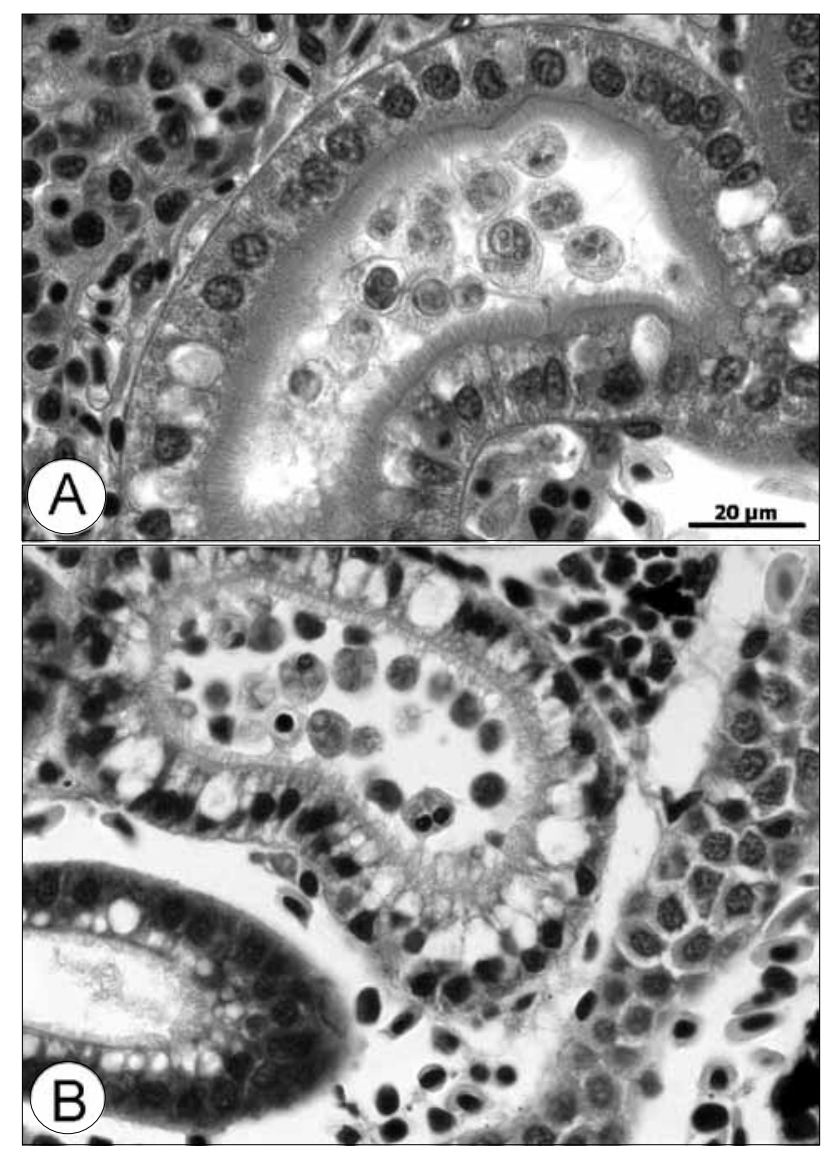

Fig. 2. Light micrographs of Sphaerospora elwhaiensis sp. $\mathrm{n}$. in kidney tubules from kokanee Oncorhynchus nerka. A - monosporous pseudoplasmodia in various stages of development (PAS stain); B - peripheral arrangement of developing pseudoplasmodia, showing evidence of epithelial cell vacuolation in affected tubule (Gram stain).

Prevalence: 79 of 177 (45\%) examined over 5 years.

Specimens deposited: Hapantotype and parahapantotype slides lodged in the Canadian Museum of Nature, with catalogue numbers CMNPA 2010-0019 and CMNPA 20100020, respectively.

E t y m o log y: The specific name derives from the Elwha River watershed in which the parasite was first observed.

Remarks. Host specimens belonging to the non-anadromous form of sockeye salmon, also known as kokanee, were in spawning condition at the time of sampling. Host size varied among years: mean fork length in 2007 was significantly greater than that in 2008 and $2009(\mathrm{p}<0.01$ for both years) (Table 2). However, there was no evidence that prevalence of infection was related to fish length.

Pseudoplasmodia in various stages of development occurred peripherally within the lumen of the proximal kidney tubules and were occasionally observed in the distal and collecting tubules (Fig. 2). Processes of the outer cell membrane of the developing pseudoplasmodium were occasionally observed to interdigitate with microvilli or cilia (Fig. 3). Vacuolation of tubule epithelial cells was occasionally associated with affected tubules and the vacuoles
Table 2. Mean size of kokanee, Oncorhynchus nerka sampled from Lake Sutherland and the prevalence of Sphaerospora elwhaiensis sp. $\mathrm{n}$.

\begin{tabular}{cccccc}
\hline Year & \multicolumn{2}{c}{ Kokanee } & \multicolumn{2}{c}{ Number (\%) infected } \\
\hline & $\mathrm{n}$ & length $^{1}(\mathrm{~mm})$ & weight $^{1}(\mathrm{~g})$ & histology & $\mathrm{PCR}^{2}$ \\
2005 & 30 & - & - & $10(33.3)$ & - \\
2006 & 32 & - & - & $26(81.3)$ & $16(80.0)$ \\
2007 & 45 & $340.5 \pm 34.9$ & $432.1 \pm 120.9$ & $22(48.9)$ & $29(72.5)$ \\
2008 & 30 & $290.5 \pm 33.4$ & $315.0 \pm 98.1$ & $12(40.0)$ & $37(92.5)$ \\
2009 & 40 & $296.8 \pm 23.8$ & $339.4 \pm 81.9$ & $9(22.5)$ & $11(27.5)$ \\
\hline
\end{tabular}

${ }^{1}$ mean $\pm 1 \mathrm{SD} ;{ }^{2}$ sample sizes for PCR are 20, 40, 40 and 40 for 2006-2009.

contained neither lipid nor glycogen. Based on histology, the estimate of prevalence in 2006 was higher $(\mathrm{p}<0.01)$ than in all other years (Table 2), and there were no statistically significant differences in prevalence among 2005, 2007 and 2008. The prevalence in 2009 was lower $(\mathrm{p}<0.01)$ than in 2007 (Table 2). A diagnostic PCR which amplified a 638 base-pair (bp) segment of SSU rDNA (primers SK1F and SK6R, Table 1) was also used to determine presence or absence of infection. In 2008, the diagnostic PCR amplified $S$. elwhaiensis $18 \mathrm{~S}$ rDNA from a higher percentage $(\mathrm{p}<0.01)$ of fish than were found to be infected by using histology (Table 2).

A 1595 bp partial sequence of SSU rDNA RNA gene was obtained from $S$. elwhaiensis by using the Myx1F and MX3R primers. This sequence and one of $2252 \mathrm{bp}$ from the large subunit (LSU) rDNA were deposited in GenBank under accession numbers EU371498 and HQ450772, respectively. Pairwise genetic distances between $S$. elwhaiensis SSU and the six most similar BLASTn-derived homologous sequences ranged from $0.041 \pm 0.007$ (Zschokkella sp., FJ361238) to $0.074 \pm 0.009$ (Chloromyxum trijugum, AY954689). A similar comparison with seven other Sphaerospora spp. yielded genetic distances that ranged from 0.164 (S. oncorhynchi, AF201373) to 3.245 (S. dicentrarchi, FJ417074).

Sphaerospora elwhaiensis SSU and LSU rDNA sequences clustered within the freshwater Myxidium clade and, based on the estimated nodal support in ML, MP and BI analyses, were most closely related to Zschokkella sp. (DDI-2008). The relatively long-branch of Zschokkella sp. (DDI-2008) however, showed the distinct phylogenetic status of these two taxa (Fig. 4). In contrast, phylogenetic relationships to other species within the freshwater Myxidium clade were not clear due to the low nodal supports (Fig. 4). Single and combined SSU and LSU rDNA phylogenetic analyses were almost congruent and both suggested that $S$. elwhaiensis occurs in a basal position to a group consisting of Myxidium cuneiforme, Zschokkella parasiluri, Zschokkella sp. 3 IF-2006 and Z. nova. In contrast to the analysis of SSU rDNA, LSU and combined SSU+LSU rDNA analyses suggested $S$. elwhaiensis is closely related to Myxidium chelonarum. This, along with the different position of Myxidium cuneiforme, is the only difference revealed by SSU and LSU rDNA analyses (Fig. 5a). 


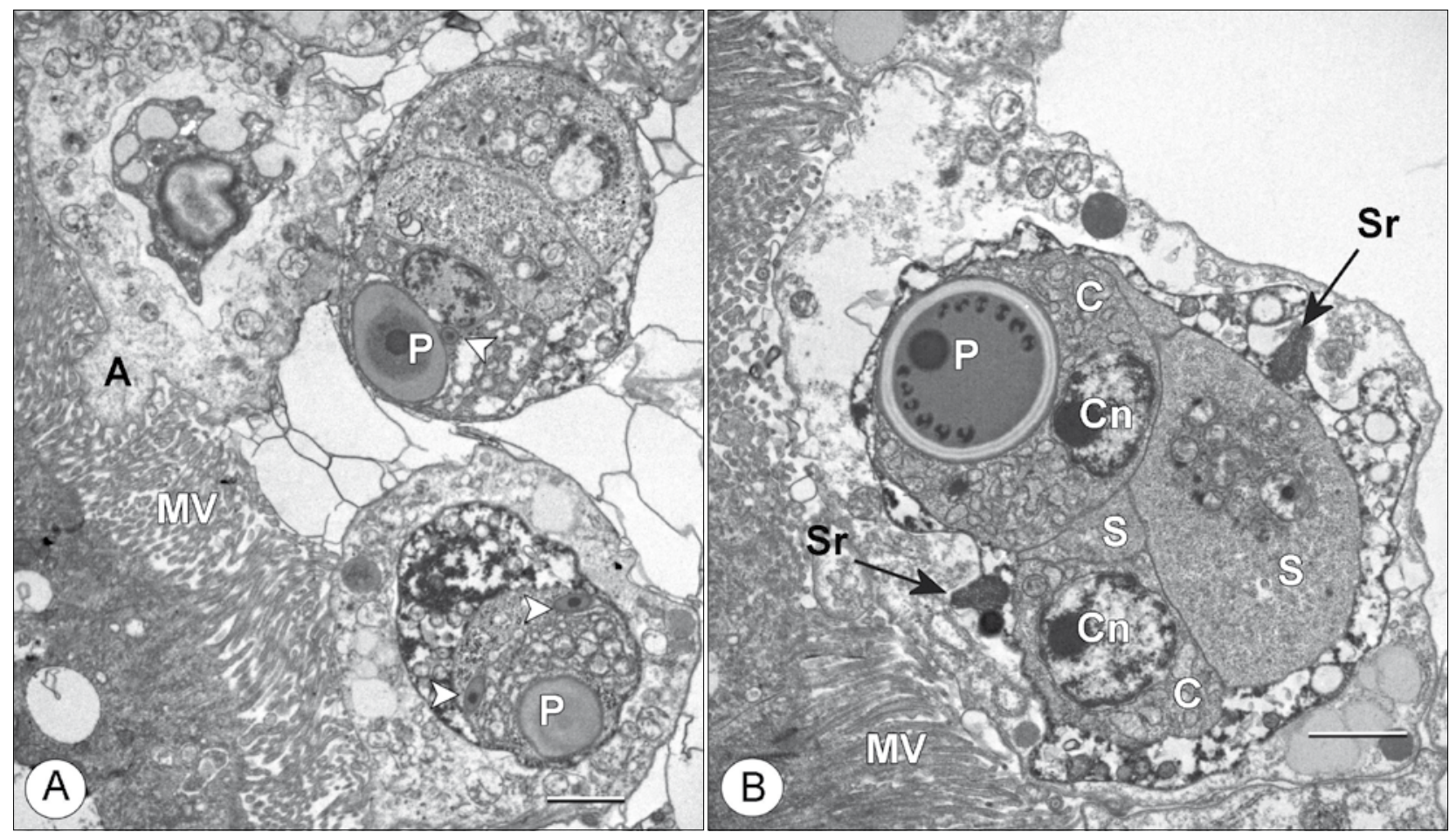

Fig. 3. Electron micrographs of Sphaerospora elwhaiensis sp. n. in kidney from kokanee Oncorhynchus nerka. A - Sporoblasts showing capsular primordia (P) and profiles of the external tube (arrowheads). The cell membrane of one pseudoplasmodium interdigitates with microvilli (MV) via an anchor-like structure (A). B - Late sporoblast showing sporogenic cell (S), capsulogenic cell (C), nucleus of capsulogenic cell (Cn) and sutural ridge of valvogenic cells (Sr). Scale bars $=2 \mu \mathrm{m}$.

The stability of S. elwhaiensis in the phylogenetic tree was examined by selection of non-conservative characters in the alignment. Datasets generated by less stringent GBlocks parameters (longer alignment with more variable characters, but with higher probability of nonhomology) resulted in a close relationship of $S$. elwhaiensis with Sphaeromyxa spp. In contrast, datasets generated by more stringent parameters resulted in a close relationship between S. elwhaiensis and Myxidium cuneiforme, Zschokkella parasiluri, Zschokkella sp. 3 IF-2006 and $Z$. nova (two selected tree topologies are shown in Fig. 5b).

\section{DISCUSSION}

The meristic, morphologic and developmental characteristics of the sphaerosporid from kokanee were novel and when combined with host information, supported the establishment of the parasite as a new species within the genus Sphaerospora. The valves of S. elwhaiensis myxospores have prominent sculpting, as do those of an unnamed sphaerosporid from rainbow trout from the American River hatchery in California and from the Aberdeen hatchery in Washington State, approximately $75 \mathrm{~km}$ from Lake Sutherland (Hedrick et al. 1988). In contrast, myxospores of Sphaerospora oncorhynchi and of S. truttae lack conspicuous valvular sculpting, whereas those of $S$. coregoni are laterally thickened (Fischer-Scherl et al. 1986, Kent et al. 1993, El-Matbouli et al. 1995). The pseudoplasmodia of $S$. elwhaiensis and S. oncorhynchi are mo- nosporous, whereas those of $S$. truttae and $S$. coregoni are disporous. Both monosporous and disporous plasmodia were observed in rainbow trout from the American River hatchery (Hedrick et al. 1988). Finally, fresh myxospores of $S$. elwhaiensis were similar in size $(10.5 \mu \mathrm{m}$ length, $11.4 \mu \mathrm{m}$ thickness) to those of $S$. oncorhynchi $(9.1 \mu \mathrm{m}$ length, $10.4 \mu \mathrm{m}$ thickness) but larger than those of S. truttae ( $6.8 \mu \mathrm{m}$ length, $8.8 \mu \mathrm{m}$ thickness). In histological preparations, the myxospores of $S$. elwhaiensis were similar in size (7.1 $\mu \mathrm{m}$ length, $8.5 \mu \mathrm{m}$ thickness) to those from the rainbow trout at the American River hatchery (6.1 $\mu \mathrm{m}$ length, $7.1 \mu \mathrm{m}$ thickness). The myxospores of S. elwhaiensis were significantly smaller in histological preparations compared with fresh material, indicating that histological processing affected the dimensions of the myxospore. Although these observations suggest that S. elwhaiensis shares morphological similarities with the parasite from the rainbow trout in California, analysis of ribosomal gene sequences will be required to adequately assess their identities. Other Sphaerospora spp. reported from non-salmonid freshwater and marine fishes in western North America include S. elegans Thélohan, 1892 in three-spined stickleback Gasterosteus aculeatus L. (see Lester 1974, Kent et al. 1998), S. cristata Shulman, 1962 in burbot Lota lota (L.) (see Arthur et al. 1976), S. araii Arthur et Lom, 1985 in longnose skate Raja rhina Jordan et Gilbert (see Arthur and Lom 1985) and an unidentified species in chub Gila bicolor Girard (see Hedrick et al. 1988). 


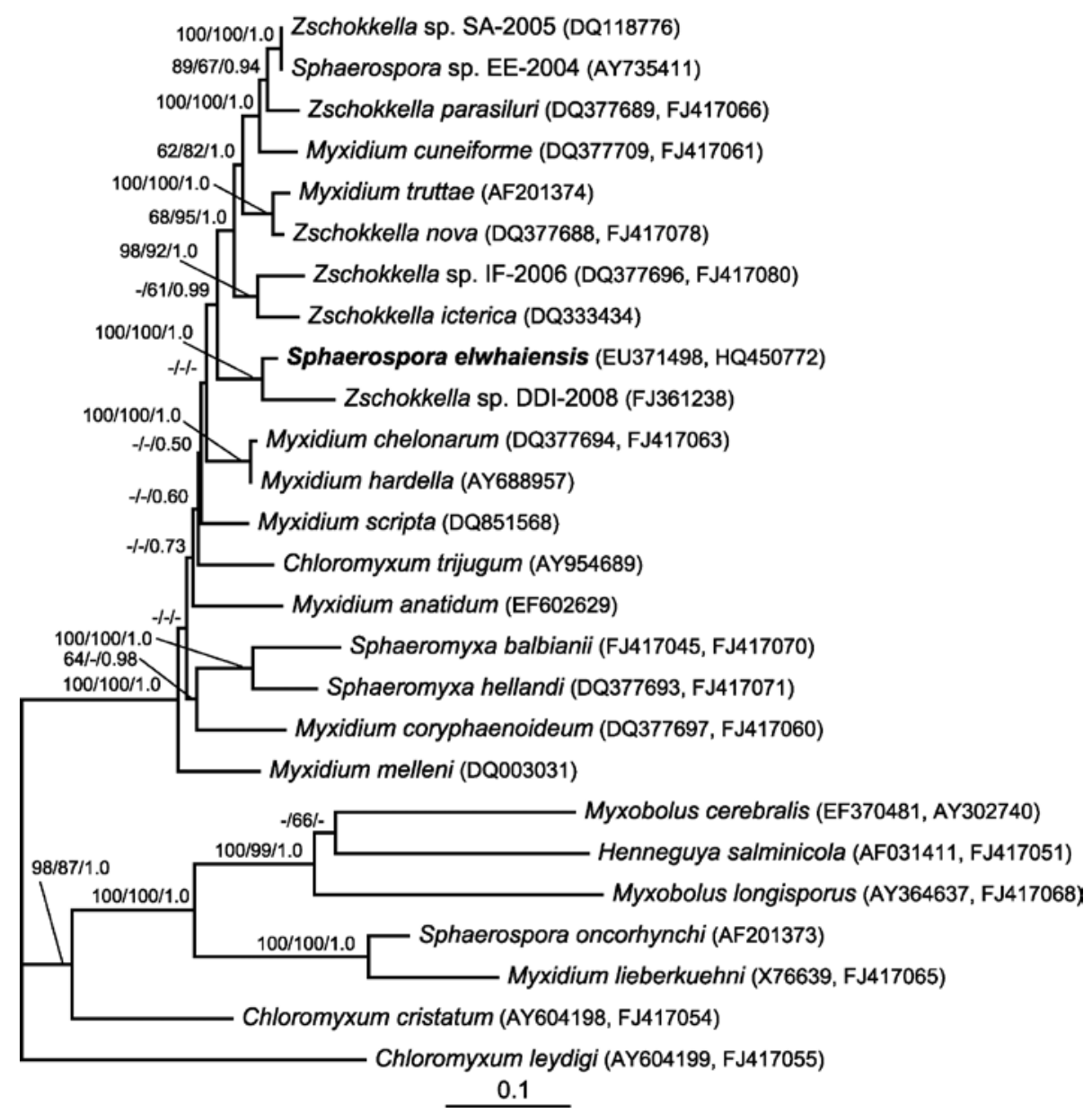

Fig. 4. Maximum likelihood tree $(-\ln =30334.2375)$ based on combined SSU and LSU rDNA data showing the phylogenetic position of Sphaerospora elwhaiensis sp. n. Nodal supports are indicated (ML/MP/BI) for the nodes with values higher than $50 \%$ (ML and MP) or 0.50 (BI). The GenBank accession numbers are stated for SSU rDNA and, if available, for LSU rDNA. The scale bar is given under the tree.

Ribosomal RNA gene sequences have also been used to assist in the taxonomy of sphaerosporid myxosporeans (Fiala 2006). The small subunit ribosomal RNA gene sequence (SSU rDNA) amplified from S. elwhaiensis showed greatest similarity to a homologous sequence from Zschokkella sp. (GenBank No. FJ361238). With the exception of S. truttae and S. ranae (Morelle, 1929), whose SSU rDNA sequences form a clade that is monophyletic with that of the type species $S$. elegans, SSU sequences from other Sphaerospora spp. occur among numerous myxosporean clades (Jirků et al. 2007), indicating that the genus Sphaerospora as defined by using myxospore morphology, is a polyphyletic assemblage of species whose nucleotide sequences display affinities both to freshwater and marine lineages (Fiala 2006). The convergence to a sphaerospore morphotype among these genetically divergent groups has led to the conclusion that this form represents a basal or primitive condition within the phylum (Jirků et al. 2007, Fiala and Bartošová 2010). Results from the phylogenetic analyses conducted on SSU and LSU rDNA sequences from S. elwhaiensis were consistent with the proposed polyphyletic origin of the genus and revealed that the species has evolved with freshwater species of Zschokkella and Myxidium. The present work confirmed the clustering of sphaerosporids observed earlier within this group, including the relatedness of an unidentified Sphaerospora sp. from goldfish to Myxidium truttae (Eszterbauer and Székely 2004). The latter two kidney myxozoans are the exceptions to the hypothesis of phylogenetic grouping according to site of infection (Holzer et al. 2004) and our data suggest they evolved from an ancestral Myxidium sp. or Zschokkella sp. infecting the gall bladder. Furthermore, the present analysis indicates that $S$. elwhaiensis is not a close relative of $S$. oncorhynchi, a parasite of the kidney of anadromous sockeye salmon in western Canada. Jirků et al. (2007) suggested that the definition of the genus Sphaerospora (sensu lato) be emended to include the presence of expansion segments within the V4 region of the SSU rRNA gene (Holzer et al. 2007), detected so far in the SSU rDNA of $S$. elegans, $S$. truttae and S. ranae. However, in the absence of DNA sequence information for many myxozoan 
a

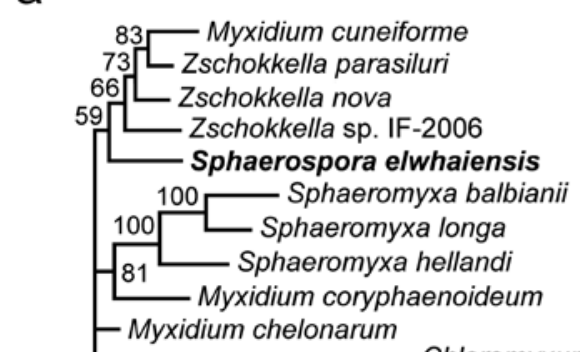

Chloromyxum cristatum

b

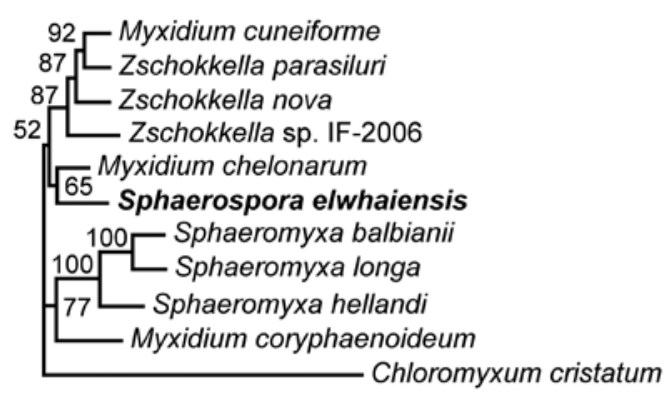

0.1
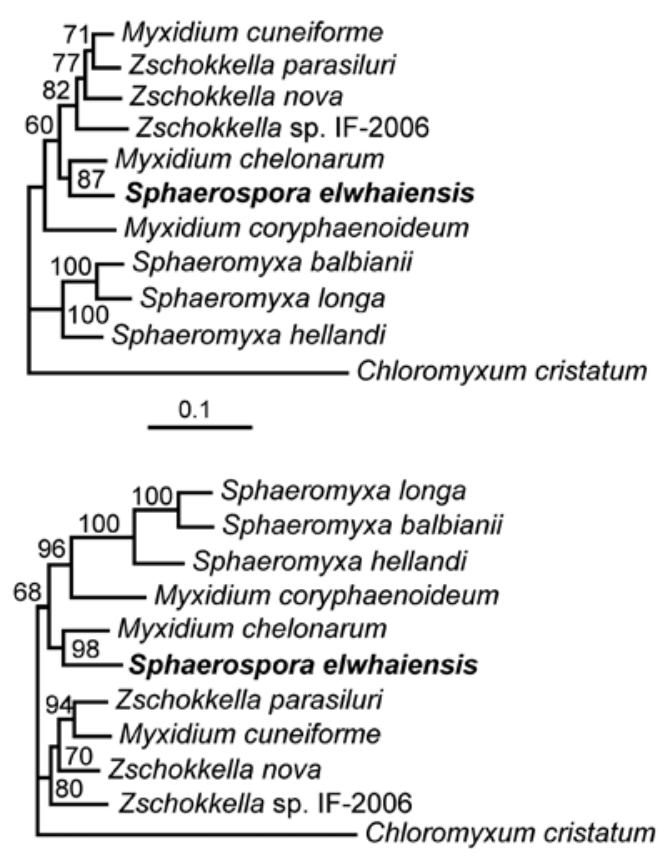

0.1

Fig. 5. Maximum likelihood tree topologies constructed under different alignments. a - comparison of trees based on SSU (left) and LSU rDNA (right) data; ambiguous characters removed from alignment by GBlocks with default parameters; $\mathbf{b}$ - comparison of trees based on combined SSU+LSU rDNA data; ambiguous characters removed by GBlocks with more stringent parameters (left, 1981 removed characters) and less stringent parameters (right, 1072 removed characters). ML bootstrap supports ( $>50 \%)$ are given by the nodes. The scale bars are given under the trees. The GenBank accession numbers are given in Fig. 4 except for Sphaeromyxa longa (DQ377691 for SSU rDNA and FJ417072 for LSU rDNA).

species and the absence of molecular characters to unify other myxozoan genera, we consider it most valuable to future taxonomic efforts to continue to assign organisms to the genus Sphaerospora based on criteria listed earlier (Lom and Dyková 2006).

Phylogenetic relationships among species of the freshwater Myxidium clade are not well resolved based on SSU rDNA analysis alone (Fiala 2006). By adding more characters, the combined SSU and LSU rDNA analysis was intended to provide a more reliable estimate of phylogeny. Although this combined analysis did not appear to improve the support observed at several nodes of myxosporean SSU+LSU rDNA phylogeny (Bartošová et al. 2009), congruent SSU and LSU rDNA tree topologies confirmed the correct placement of $S$. elwhaiensis within the freshwater Myxidium clade. Despite this, the exact phylogenetic position of $S$. elwhaiensis is uncertain, depending partially on the exclusion of non-conservative characters using different GBlocks parameters during construction of the alignments.

Sphaerospora elwhaiensis has been described from non-anadromous sockeye salmon inhabiting Lake Sutherland in Washington, USA. The parasite was shown to conform to morphological characteristics of the genus and was distinct from congeneric parasites of salmonids. Small subunit ribosomal RNA gene sequence data pro- vided additional evidence for the polyphyletic relationship among members of the genus. Further research is required to understand the life cycle of $S$. elwhaiensis in Lake Sutherland and to determine the pathological consequences of $S$. elwhaiensis infections in kokanee. Vacuolation of tubule epithelial cells has previously been reported during infections with Sphaerospora epinepheli Fischer-Scherl, Hoffmann et Boonyaratpalin, 1990 in the grouper Epinephelus malabaricus Bloch et Schneider (see Supamattaya et al. 1993). However, a lag of 3-4 hr between capture and sampling raises the possibility that vacuolation of tubule epithelial cells in kokanee was a postmortem artifact, possibly exacerbated by the infection.

Acknowledgements. Funding for this research was provided by Fisheries and Oceans Canada (FOC) and the Grant Agency of the Czech Republic (204/09/P519). We thank W. Bennett, FOC, for conducting the PAS and Sudan black histological staining and Ms. S. Jones for preparing the line drawings. Ms. D. Wadowska, Atlantic Veterinary College, University of Prince Edward Island processed tissues for transmission electron microscopy and provided electron micrographs. We also thank all of those who helped collect and sample the kokanee from Lake Sutherland including Larry Ward, Mel Elofson, Mike McHenry, Mitch Boyd, Larry Henderson, Keith Lauderbach, Sonny Sampson and Raymond Moses, Lower Elwha Klallam Tribe, Dan Collins, Washington Department of Fish and Wildlife, and Sharon Lutz, U.S. Fish and Wildlife Service. 
Andree K.B., MacConnell E., Hedrick R.P. 1998: A nested polymerase chain reaction for the detection of genomic DNA of Myxobolus cerebralis in rainbow trout Oncorhynchus mykiss. Dis. Aquat. Org. 34: 145-154.

Arthur J.R., Lom J. 1985: Sphaerospora araii n. sp. (Myxosporea: Sphaerosporidae) from the kidney of a longnose skate (Raja rhina Jordan and Gilbert) from the Pacific Ocean off Canada. Can. J. Zool. 63: 2902-2906.

Arthur J.R., Margolis L., Arai H.P. 1976: Parasites of fishes of Aishihik and Stevens lakes, Yukon Territory, and potential consequences of their interlake transfer through a proposed water diversion for hydroelectrical purposes. J. Fish. Res. Board Can. 33: 2489-2499.

Bartošová P., Fiala I., Hypša V. 2009: Concatenated SSU and LSU rDNA data confirm the main evolutionary trends within myxosporeans (Myxozoa: Myxosporea) and provide effective tool for their molecular phylogenetics. Mol. Phylogenet. Evol. 53: 81-93.

Bennett R.O., Wolke R.E. 1986: A Sphaerospora-like myxosporidean from the kidneys of Atlantic salmon (Salmo salar). J. Wildl. Dis. 22: 268-271.

Brenkman S.J., Mumford S.L., House M., Patterson C. 2008: Establishing baseline information on the geographic distribution of fish pathogens endemic in Pacific salmonids prior to dam removal and subsequent recolonization by anadromous fish in the Elwha River, Washington. Northw. Sci. 82: 142-152.

Castresana J. 2000: Selection of conserved blocks from multiple alignments for their use in phylogenetic analysis. Mol. Biol. Evol. 17: 540-552

El-Matbouli M., Hoffmann R.W., Kern R. 1995: Sphaerospora coregoni n. sp. (Myxosporea: Sphaerosporidae) observed in the kidney of whitefish (Coregonus lavaretus). Bull. Eur. Assoc. Fish Pathol. 15: 132-133.

Eszterbauer E., SzéKely C. 2004: Molecular phylogeny of the kidney-parasitic Sphaerospora renicola from common carp (Cyprinus carpio) and Sphaerospora sp. from goldfish (Carassius auratus auratus). Acta Vet. Hung. 52: 469-478.

Fiala I. 2006: The phylogeny of Myxosporea (Myxozoa) based on small subunit ribosomal RNA gene analysis. Int. J. Parasitol. 36: 1521-1534.

Fiala I., Bartošová P. 2010: History of myxozoan character evolution on the basis of rDNA and EF-2 data. BMC Evol. Biol. 10: 228.

Fischer-Scherl T., El-Matbouli M., Hoffmann R.W. 1986: A new Sphaerospora sp. in brown trout (Salmo trutta m. fario) in Germany. Bull. Eur. Assoc. Fish Pathol. 6: 16-19.

Hallett S.L., Diamant A. 2001: Ultrastructure and small-subunit ribosomal DNA sequence of Henneguya lesteri n. sp. (Myxosporea), a parasite of sand whiting Sillago analis (Sillaginidae) from the coast of Queensland, Australia. Dis. Aquat. Org. 46: 197-212.

Hedrick R.P., Kent M.L., Toth R.J., Morrison J.K. 1988: Fish infected with Sphaerospora spp. Thélohan (Myxosporea) from waters enzootic for proliferative kidney disease of salmonids. J. Protozool. 35: 13-18.

Hillis D.M., Dixon M.T. 1991: Ribosomal DNA - molecular evolution and phylogenetic inference. Q. Rev. Biol. 66: 410-453.

Holzer A.S., Sommerville C., Wootten R. 2004: Molecular relationships and phylogeny in a community of myxosporeans and actinosporeans based on their $18 \mathrm{~S}$ rDNA sequences. Int. J. Parasitol. 34: 1099-1111.
Holzer A.S., Wootten R., Sommerville C. 2007: The secondary structure of the unusually long $18 \mathrm{~S}$ ribosomal RNA of the myxozoan Sphaerospora truttae and structural evolutionary trends in the Myxozoa. Int. J. Parasitol. 37: 1281-1295.

JirkU゚ M., Fiala I., Modrý D. 2007: Tracing the genus Sphaerospora: redescription and phylogeny of the Sphaerospora ranae (Morelle, 1929) n. comb. (Myxosporea, Sphaerosporidae), with emendation of the genus Sphaerospora. Parasitology 134: 1727-1739.

Jones S., Prosperi-Porta G., Dawe S. 2006: A new parvicapsulid (Myxosporea) species in adult pink salmon, Oncorhynchus gorbuscha, from the Quinsam River, British Columbia, Canada. J. Parasitol. 92: 1313-1318.

Katoh K., Misawa K., Kuma K., Miyata T. 2002: MAFFT: a novel method for rapid multiple sequence alignment based on fast Fourier transform. Nucl. Acids Res. 30: 3059-3066.

Kent M.L., Khattra J., Hervio D.M.L., Devlin R.H. 1998: Ribosomal DNA sequence analysis of isolates of the PKX myxosporean and their relationship to members of the genus Sphaerospora. J. Aquat. Anim. Health 10: 12-21.

Kent M.L., Whitaker D.J., Margolis L. 1993: Sphaerospora oncorhynchi n. sp. (Myxosporea: Sphaerosporidae) from the kidney of sockeye salmon (Oncorhynchus nerka) in British Columbia and its possible relationship to the myxosporean causing proliferative kidney disease in salmonid fishes. Can. J. Zool. 71: 2425-2430.

Lester R.J.G. 1974: Parasites of Gasterosteus aculeatus near Vancouver, British Columbia. Syesis 7: 195-200.

Lom J. 1969: On a new taxonomic character in Myxosporidia, as demonstrated in descriptions of two new species of Myxobolus. Folia Parasitol. 16: 97-103.

Lom J., Dykové I. 2006: Myxozoan genera: definition and notes on taxonomy, life-cycle terminology and pathogenic species. Folia Parasitol. 53: 1-36.

McGeorge J., Sommerville C., Wootten R. 1997: Studies on the actinosporean stages parasitic in oligochaetes from the sediments of a hatchery where Atlantic salmon harbour Sphaerospora truttae infection. Dis. Aquat. Org. 30: 107-119.

Nylander J.A.A. 2004: MrModeltest v2. Program distributed by the author. Evolutionary Biology Centre, Uppsala University.

Posada D., Crandall K.A. 1998: Modeltest: testing the model of DNA substitution. Bioinformatics 14: 817-818.

Ronquist F., Huelsenbeck J.P. 2003: MrBayes 3: Bayesian phylogenetic inference under mixed models. Bioinformatics 19: $1572-1574$.

Supamattaya K., Fischer-Scherl T., Hoffmann R.W., BoonYARATPALIN S. 1993: Light and electron microscope observations on presporogonic and sporogonic stages of Sphaerospora epinepheli (Myxosporea) in grouper (Epinephelus malabaricus). J. Euk. Microbiol. 40: 71-80.

Swofford D.L. 2001: PAUP*: Phylogenetic Analysis Using Parsimony (*and other methods), Version 4.0b8. Sinauer Associates, Sunderland, Massachusetts.

Tamura K., Dudley J., Nei M., Kumar S. 2007: MEGA4: Molecular Evolutionary Genetics Analysis (MEGA) software version 4.0. Mol. Biol. Evol. 24: 1596-1599.

Walter G., Odening K., Bockhardt I. 1991: Sphaerospora truttae (Myxosporidia) in Salmo trutta and Thymallus thymallus: first detection in Thüringia and in the Hartz region and also in the grayling. Angew. Parasitol. 32: 113-119. 